\title{
Base-Promoted Ring Contraction of Dihydrodiazepinones to Pyrrolinones
}

\author{
Anastasia A. Fesenko, Anatoly D. Shutalev* \\ Department of Organic Chemistry, Moscow State University of Fine Chemical Technologies, \\ 86 Vernadsky Avenue, 119571 Moscow, Russian Federation
}

\begin{abstract}
A novel synthesis of 2,3-dihydro-1H-1,3-diazepin-2-ones based on thermal elimination of methanol from 4-methoxy-2,3,4,5-tetrahydro-1H-1,3-diazepin-2-ones has been developed. The prepared dihydrodiazepinones underwent a new rearrangement under basic conditions to give 3(aminomethylene)-2,3-dihydro-1H-pyrrol-2-ones. Plausible mechanism for the rearrangement is proposed.
\end{abstract}

\section{Keywords}

1H-1,3-Diazepin-2-ones; Ring contraction; 2,3-dihydro-1H-pyrrol-2-ones; Anti-aromaticity

\section{Introduction}

The development of general approaches to rare heterocyclic scaffolds and studies of their structure and reactivity is important from the viewpoint of synthetic, theoretical and medicinal chemistry. These scaffolds are represented by monocyclic 1,3-diazepines and their partly hydrogenated derivatives. ${ }^{1}$ General strategies for their synthesis include various ring expansion reactions. ${ }^{2-4}$ For example, photolysis of 2-azidopyridines or their bicyclic isomers, tetrazolo[1,5-a]pyridines, in the presence of water, alcohols or secondary amines gives access to 2,3-dihydro-1H-1,3-diazepin-2-ones, 2-alkoxyand 2-dialkylamino-1H-1,3-diazepines, respectively. ${ }^{4}$ The drawbacks of these methods are the poor availability of the starting compounds, limited possibilities for diversification, multistep syntheses, small-scale preparations, harsh reaction conditions, poor yields, etc. Therefore, the chemistry of these compounds remains under-explored. The only reactions described are their photochemical transformations into 2,4-diazabicyclo[3.2.0] heptane $\mathrm{e}^{4 \mathrm{e}, \mathrm{g}}$ and pyrrole $^{4 \mathrm{~g}, \mathrm{f}}$ derivatives. Here we report a new and convenient synthesis of 5-functionalized 2,3-dihydro-1H-1,3-diazepin-2-ones and their rearrangements into 3-(aminomethylene)-2,3-dihydro-1H-pyrrol-2-ones or 1-carbamoyl-1H-pyrroles promoted by bases or acids, respectively. 


\section{Results and discussion}

We previously developed a general five-step synthesis of 6-functionalized 2,3,4,5-tetrahydro-1H-1,3diazepin-2-ones 1 based on the ring expansion of 1,2,3,4-tetrahydropyrimidin-2-ones 2 mediated by nucleophiles (Scheme 1). ${ }^{5}$

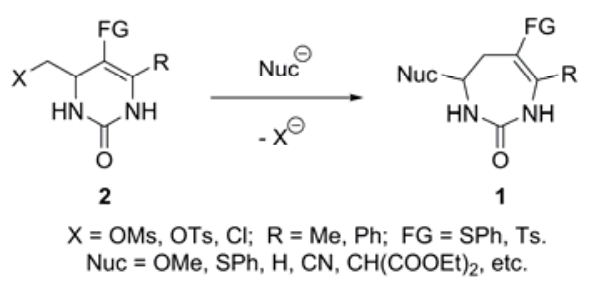

Scheme 1. Nucleophile-mediated ring expansion of tetrahydropyrimidin-2-ones 2 into tetrahydro-1,3-diazepin-2-ones $\mathbf{1 .}$

In continuation of this research, we studied the thermal stability of solutions of 4-methoxy- (3a-c) and 4-phenylthio-substituted diazepinones (3d-f) and found that above $90-100{ }^{\circ} \mathrm{C}$, these compounds eliminated $\mathrm{MeOH}$ or PhSH to give 2,3-dihydro-1H-1,3-diazepin-2-ones 4a-c (Scheme 2).

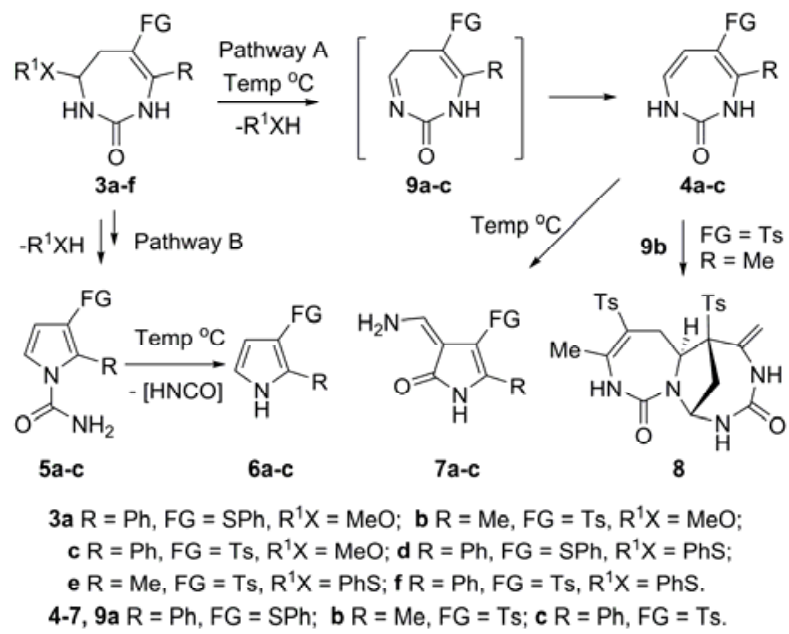

Scheme 2. Thermolysis of 4-methoxy- and 4-phenylthio-substituted tetrahydro-1,3-diazepin-2-ones 3a-f.

Initially, we studied the thermolysis of compounds 3a-f using ${ }^{1} \mathrm{H}$ NMR spectroscopy. We heated DMSO- $d_{6}$ solutions of 3a-f in NMR tubes at different temperatures and time intervals, and then determined the compositions of the reaction mixtures (at $25{ }^{\circ} \mathrm{C}$ ). Selected data are summarized in Table 1.

Table 1 shows that thermolysis of tetrahydrodiazepinones 3a-f resulted in the corresponding dihydrodiazepinones $\mathbf{4 a - c}$ as the major products. Conversion of the starting material strongly depended 
on the substituent at the $\mathrm{C} 4$ position. The rate of transformation of phenylthio diazepinones 3d-f was lower than those of methoxy derivatives 3a-c (entries 1, 2 and 6 vs entries 10,11 and 13, respectively), probably due to the poorer leaving group ability of the phenylthio group compared with a methoxy group.

Table 1. Product distribution upon thermolysis of 3a-f and 4a-c in DMSO- $d_{6}$.

\begin{tabular}{llllllllll}
\hline \multicolumn{1}{c}{ Entry } & $\mathbf{3}$ or & \multicolumn{1}{c}{ Temp, ${ }^{a}$ Time, } & $\mathbf{3}$ & $\mathbf{4}$ & $\mathbf{5}$ & $\mathbf{6}$ & $\mathbf{7}$ & $\mathbf{8}$ \\
& $\mathbf{4}$ & $\left({ }^{\circ} \mathrm{C}\right)$ & $(\mathrm{h})$ & & & & & & \\
\hline 1 & 3a & 132 & 0.5 & 0 & 91 & 7 & 0 & 2 & - \\
2 & 3b & 132 & 0.5 & 0 & 83 & 1 & 9 & 6 & 1 \\
3 & 3c & 98 & 2.2 & 13 & 59 & 1 & 24 & 3 & - \\
4 & 3c & 122 & 1.0 & 45 & 42 & 1 & 9 & 3 & - \\
5 & 3c & 122 & 2.0 & 0 & 42 & 1 & 35 & 22 & - \\
6 & 3c & 135 & 0.5 & 0 & 71 & 0 & 20 & 9 & - \\
7 & 3d & 98 & 2.2 & 43 & 46 & 9 & 1 & 1 & - \\
8 & 3d & 108 & 4.0 & 19 & 67 & 11 & 2 & 1 & - \\
9 & 3d & 108 & 7.3 & 0 & 71 & 16 & 7 & 6 & - \\
10 & 3d & 132 & 0.5 & 30 & 63 & 6 & 0 & 1 & - \\
11 & 3e & 132 & 0.5 & 55 & 40 & 3 & 1 & 1 & 0 \\
12 & 3e & 136 & 2.0 & 7 & 66 & 8 & 4 & 15 & 0 \\
13 & 3f & 132 & 0.5 & 69 & 27 & 2 & 2 & 0 & - \\
14 & 4a & 136 & 3.1 & - & 78 & 0 & 0 & 22 & - \\
15 & 4b & 136 & 4.7 & - & 32 & 0 & 9 & 59 & 0 \\
16 & 4c & 136 & 4.8 & - & 17 & 2 & 3 & 78 & - \\
& & & & & & & & &
\end{tabular}

\footnotetext{
${ }^{\mathrm{a}}$ Oil bath temperature $\left( \pm 1.5^{\circ} \mathrm{C}\right)$.

${ }^{\mathrm{b}}$ According to ${ }^{1} \mathrm{H}$ NMR spectroscopic data.
}

Some other products, 1-carbamoyl-1H-pyrroles 5a-c, $1 H$-pyrroles 6a-c, 3-(aminomethylene)-2,3dihydro-1H-pyrrol-2-ones 7a-c, and bis-diazepinone 8 (from $\mathbf{3 b}$ ) always formed along with products 4a-c. The amounts of these products obtained depended on the structure of the starting material, the temperature and the reaction time. In general, increasing the temperature and decreasing the reaction time led to an increase in the relative amounts of 4a-c (entries 3-6 and entries 8-10). Under the optimized conditions (entries 1, 2 and 6) the yields of 4a-c from 3a-c determined by ${ }^{1} \mathrm{H}$ NMR spectroscopy were $71-91 \%$. These conditions were used for the preparative synthesis of diazepinones 4a-c. Heating 3a-c in DMSO at $135{ }^{\circ} \mathrm{C}$ for 30 minutes followed by the addition of water and filtration of the formed precipitate gave products 4a-c in 53-73\% yields after silica gel column chromatography.

Scheme 2 illustrates possible routes for the transformation of substrates $\mathbf{3}$ into compounds $\mathbf{4 - 8}$ upon heating. The additional ${ }^{1} \mathrm{H}$ NMR experiments showed that prolonged heating of dihydrodiazepinones 4a-c in DMSO- $d_{6}$ at $136{ }^{\circ} \mathrm{C}$ led to their slow conversion, mainly into pyrrolones 7a-c (entries 14-16). The summarized ${ }^{1} \mathrm{H}$ NMR spectroscopic data in Table 1 confirms that the thermolysis of 3a-f proceeds via two independent pathways. Pathway A gives diazepinones 4a-c followed by their slow transformation into pyrrolones 7a-c; pathway $\mathbf{B}$ affords carbamoylpyrroles 5a-c 
and then pyrroles 6a-c. Formation of bis-diazepinone $\mathbf{8}$ upon heating of $\mathbf{3 b}$ can be explained as a result of the reaction of $\mathbf{4 b}$ with its imine tautomer $\mathbf{9 b}$ (see refs $5 \mathrm{a}, \mathrm{b}$ ). We suppose that thermal elimination of $\mathrm{MeOH}$ from 3a-c proceeds through formation of imine intermediates 9a-c followed by a tautomeric shift of hydrogen to produce more stable enamines 4a-c. Bis-diazepine 8 was not observed in the thermolysis of phenylthio-substituted diazepine 3e (entries 11 and 12), presumably due to the short life-time of $\mathbf{9 b}$ in the presence of strongly nucleophilic thiophenol. The rearrangement of dihydrodiazepinones 4a-c into pyrrolones 7a-c seems quite intriguing; its mechanism is currently under investigation and will be briefly described below.

There are several possible mechanisms underlying the transformation of tetrahydrodiazepinones 3a-f into pyrroles 5a-c. One of them could include hydrolysis of 3a-f with traces of residual water in DMSO to produce hydroxy diazepines $3\left(\mathrm{R}^{1} \mathrm{X}=\mathrm{OH}\right)$ followed by ring-opening and recyclization. However, thermolysis of diazepines 3a,c,f in refluxing toluene or xylene under strictly anhydrous conditions also gave significant amounts (up to 30\%) of pyrroles 5a,c in addition to diazepines 4a,c and other products. Therefore, we think that compounds 5a-c result from transannular attack of the N1 nitrogen at the carbon atom $\mathrm{C} 4$ of imine intermediates 9a-c to produce derivatives of 1,6-diazabicyclo[3.2.0]hept-2-en-7-one followed by C5-N6 cleavage (Scheme 3).

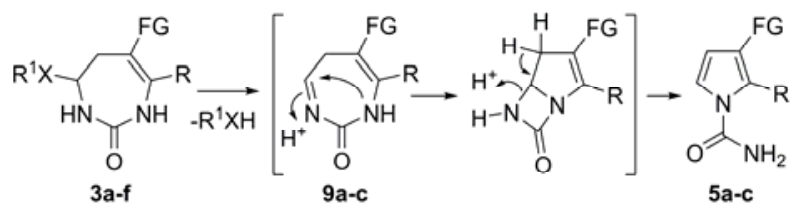

Scheme 3. Plausible pathway for the transformation of tetrahydrodiazepinones 3a-f into pyrroles 5a-c.

Formation of pyrrolones 7a-c from dihydrodiazepinones 4a-c upon thermolysis is a new and quite unusual reaction of monocyclic 1,3-diazepines. To understand the mechanism of this reaction and develop preparative syntheses of pyrrolones 7, we studied the reactivity of 4a,b and their precursors, 3a,b and 11, using basic reagents with different solvents, temperatures and reaction times (Scheme 4).

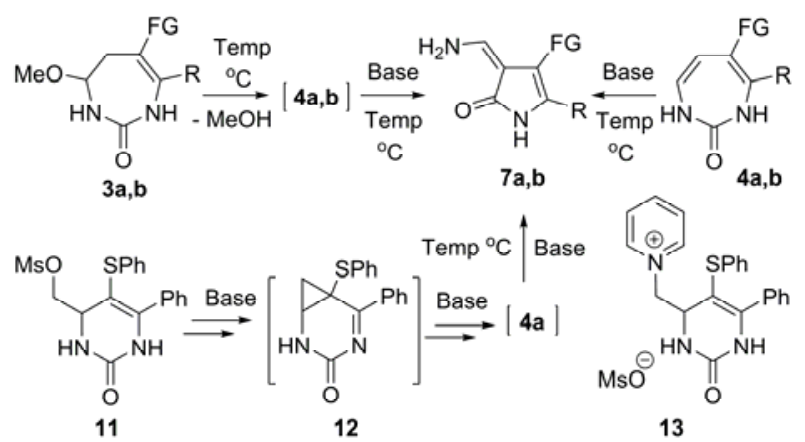

Scheme 4. Base-mediated transformations of 4a,b and their precursors 3a,b and $\mathbf{1 1}$ into pyrrolones 7a,b. 
Generally, the rate of the rearrangement of diazepinones 4a,b into pyrrolones 7a,b was increased significantly by bases and heating. Reflux of compounds 4a,b in pyridine for 7-10 hours gave pyrrolones 7a,b in excellent isolated yields (93-95\%).

Since dihydrodiazepinones $\mathbf{4 a , b}$ were obtained by thermal elimination of $\mathrm{MeOH}$ from tetrahydrodiazepinones 3a,b, we attempted to synthesize pyrrolones 7a,b directly from 3a,b. Reflux of diazepine 3a in pyridine for seven hours afforded pyrrolone 7a in 77\% yield after silica gel column chromatography. Under similar conditions diazepine $\mathbf{3 b}$ gave pyrrolone $\mathbf{7 b}$ in $92 \%$ yield.

Previously, we found that tetrahydropyrimidines 2, in the presence of strong non-nucleophilic bases, were transformed into dihydrodiazepinones (e.g., 4 and 9) via cyclopropane bicyclic intermediates (e.g., 12). ${ }^{5 \mathrm{e}}$ Reflux of $\mathbf{1 1}$ in pyridine for six hours in the presence of DBU ( 0.25 equiv) resulted in a mixture of pyrroles 5a, 6a and 7a, and pyridinium salt $\mathbf{1 3}$ in a ratio of 1:13:78:8, respectively. Pyrrolone 7a was isolated from this mixture using column chromatography in $37 \%$ yield. Compound 13 was the major product when pyrimidine 11 was refluxed in pyridine without DBU for two hours (5a:6a:7a:13 = 4:5:39:52). Therefore, we assume that the basicity of pyridine is not sufficient for proton abstraction from $\mathrm{N}_{(1)} \mathrm{H}$, which promotes the ring expansion. ${ }^{5 \mathrm{e}}$

The base-mediated rearrangement of diazepinones $\mathbf{4 a , b}$ into pyrrolones $\mathbf{7 a , b}$ seems to be extraordinary. To our knowledge, there are no reports concerning this type of transformation. In order to understand its mechanism we performed quantum chemical calculations at the B3LYP/6-31+G(d,p) level of theory for the simplest model reaction, namely the rearrangement of diazepinone 14 into pyrrolone 15 (Scheme 5).

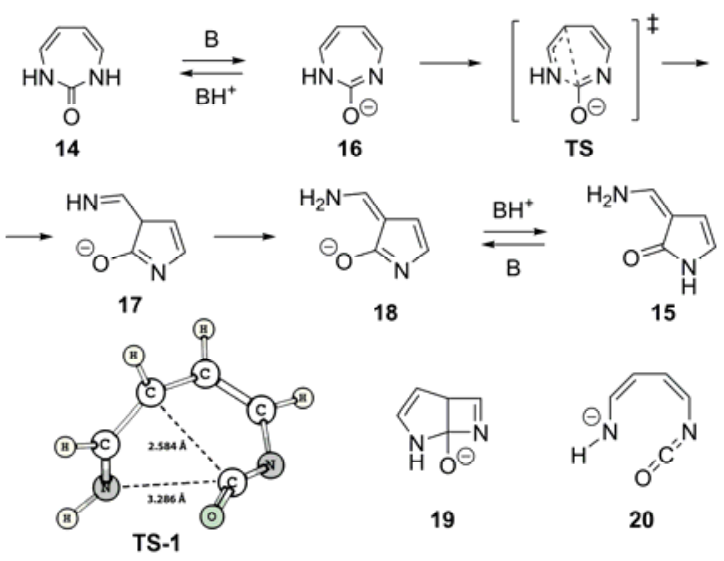

Scheme 5. A plausible pathway for the rearrangement of $\mathbf{1 4}$ into $\mathbf{1 5}$ and the calculated geometry of the transition state in pyridine solution (TS-1) (the C-C-C-C dihedral angle $=-77.67^{\circ}$ ).

First, we studied the structure of $\mathbf{1 4}$ and its conjugated base 16, from which the rearrangement presumably starts. The calculations showed that these compounds are the most stable among all the 
possible tautomers (seven for $\mathbf{1 4}$ and three for 16) in the gas phase and in DMSO or pyridine solutions using the polarizable continuum model (PCM). They are fully conjugated and their planar conformations could be expected to be anti-aromatic $8 \pi$-electron systems, ${ }^{6}$ especially for 16.

The nuclear-independent chemical shift ${ }^{7}$ (NICS) values of $\mathbf{1 4}$ and $\mathbf{1 6}$ in the optimized and planar conformations were used as a magnetic criterion of aromaticity. The NICS(0) values in the gas phase calculated at the HF/6-31+G(d) level (2.55 and 1.29 ppm for the optimized conformations of $\mathbf{1 4}$ and 16; 5.45 and 11.85 ppm for the planar conformations of $\mathbf{1 4}$ and 16, respectively) show that molecules of 14 and 16 in the planar conformations are anti-aromatic. To avoid anti-aromaticity these compounds adopt boat-like conformations with the nitrogen of the NH group and carbons of the opposite double bond out of the plane. The B3LYP/6-31+G(d,p) calculations in the gas phase, DMSO or pyridine solutions including the intrinsic reaction coordinate ${ }^{8}$ (IRC) analysis demonstrated that the planar conformations of $\mathbf{1 4}$ and $\mathbf{1 6}$ are transition states with only one imaginary vibrational frequency and energy barriers of $1.23-1.35$ and $3.65-3.82 \mathrm{kcal} / \mathrm{mol}$ for 14 and 16 , respectively.

The anion 16 possesses an extraordinarily long (practically single) C2-NH bond (e.g., $1.490 \AA$ in the gas phase) and a rather short $\mathrm{C} 2-\mathrm{N}$ bond (e.g., $1.331 \AA$ in the gas phase) compared with the length of the $\mathrm{C} 2-\mathrm{N}$ bond (1.386 $\AA$ ) in $\mathbf{1 4}$. Therefore, cleavage of the $\mathrm{C} 2-\mathrm{NH}$ bond in $\mathbf{1 6}$ is most probably the first step of the rearrangement.

The B3LYP/6-31+G(d,p) calculations also using the PCM solvation model showed that the most favorable pathway for the rearrangement, after deprotonation of the $\mathrm{NH}$ group of 14, is a concerted, one-step process including the $\mathrm{C} 2-\mathrm{NH}$ bond cleavage in $\mathbf{1 6}$ with simultaneous rotation around the C4C5 single bond and proceeding via anionic transition states (TS) (Scheme 5). The IRC analysis demonstrated that the found transition states connect the desired minima. The energy barriers (from 16 to TS) were $30.27,34.01$ and $33.70 \mathrm{kcal} / \mathrm{mol}$ for the gas phase, DMSO and pyridine solutions, respectively (VZPE uncorrected). The product of this reaction, imino-derivative 17, after the imineenamine tautomerization into $\mathbf{1 8}$ followed by protonation was converted into the target compound $\mathbf{1 5 .}$

Rearrangement of dihydrodiazepinone anion 16 into pyrrolone anion 17 could also proceed via intermediate formation of 2,7-diazabicyclo[3.2.0]hepta-3,6-dien-1-olate (19) or conjugated base of (4isocyanatobuta-1,3-dien-1-yl)amine (20) (Scheme 5). However, the B3LYP/6-31+G(d,p) calculations showed that the corresponding energy barriers lied significantly higher than that of the concerted process.

We assume that the above one-step mechanism is also valid for the base-promoted rearrangement of dihydrodiazepinones 4a,b into pyrrolones 7a,b. Indeed, the B3LYP/6-31+G(d,p) calculated structures of these compounds and their conjugated bases (the gas phase, DMSO and pyridine solutions) are close to those of $\mathbf{1 4}$ and 16. In particular, the $\mathrm{N}_{(3)} \mathrm{H}$ deprotonated forms of $\mathbf{4 a , b}$ adopt boat-like conformations with extraordinarily long C2-NH bonds (1.480-1.490 ̊̊). The remarkable regioselectivity of the reaction proceeding exclusively via the $\mathrm{N}_{(3)} \mathrm{H}$ deprotonated forms of $\mathbf{4 a}$, b can be 
explained by the higher acidity of the $\mathrm{N}_{(3)} \mathrm{H}$ group compared with that of the $\mathrm{N}_{(1)} \mathrm{H}$ group (0.54-2.32 $\mathrm{kcal} / \mathrm{mol})$. The calculations also showed that pyrrolones 7a,b are much more stable (13.56-14.72 $\mathrm{kcal} / \mathrm{mol}$ ) than the corresponding dihydrodiazepinones $\mathbf{4 a , b}$.

\section{Conclussion}

New and convenient approach to functionalized 2,3-dihydro-1H-1,3-diazepin-2-ones based on thermal elimination of $\mathrm{MeOH}$ from 4-methoxy-2,3,4,5-tetrahydro-1H-1,3-diazepin-2-ones has been developed. Upon heating with or without bases, dihydrodiazepinones underwent an unprecedented rearrangement into 3-(aminomethylene)-2,3-dihydro-1H-pyrrol-2-ones. A plausible mechanism for the rearrangement based on quantum chemical calculations involves initial NH deprotonation followed by a concerted ring-contraction process. 3-(Aminomethylene)-2,3-dihydro-1H-pyrrol-2-ones were also obtained from the precursors of 2,3-dihydro- $1 \mathrm{H}$-1,3-diazepin-2-ones as a result of cascade reactions.

\section{Acknowledgements}

This research was financially supported by the Ministry of Education and Science of the Russian Federation (project part of government order, 4.1849.2014/K) and the Presidential Grant for Young Scientists (MK-2956.2013.3).

\section{References}

1. For reviews on 1,3-diazepines, see: (a) De Borggraeve, W. M.;Van den Bogaert, A. M. “1,3Diazepines” in Comprehensive Heterocyclic Chemistry III; Katritzky, A. R., Ramsden, C. A., Scriven, E. F. V., Taylor, J. K., Eds.; Elsevier: Oxford, 2008; Vol. 13, pp. 161-181; (b) Boyd, G. V. "Aromatic 7-ring systems with two or more heteroatoms" in Houben-Weyl: Methods of Organic Chemistry; Schumann, E., Eds.; Georg Thieme Verlag: Stuttgart, 1997; Vol. E9d, pp. 299-508; (c) Le Count, D. J. “1,3-Diazepines” in Comprehensive Heterocyclic Chemistry II; Katritzky, A. R., Rees, C. W., Scriven, E. F. V., Eds.; Elsevier: Oxford, 1996; Vol. 9, pp. 139-150.

2. For a review including 1,3-diazepine synthesis from pyrimidines, see: Fesenko, A. A.; Shutalev, A. D. Chem. Heterocycl. Compd. 2013, 49, 827-848.

3. (a) Kunieda, T.; Witkop, B. J. Am. Chem. Soc. 1969, 91, 7751-7752; (b) Troxler, F.; Weber, H. P.; Jaunin, A; Loosli, H.-R. Helv. Chim. Acta 1974, 57, 750-764; (c) Ashby, J.; Griffiths, D. J. J. Chem. Soc., Perkin Trans. 1, 1975, 657-662; (d) Bullock, E.; Garter, R. A.; Cochrane, R.; Gregory, B.; Shields, D. C. Can. J. Chem., 1977, 55, 895-905; (e) Claremon, D. A.; Rosenthal, S. A. Synthesis 1986, 664-665; (f) Michels, G.; Mynott, R.; Regitz, M. Chem. Ber. 1988, 121, 357-361; (g) Yamazaki, C.; Katayama, K.; Suzuki, K. J. Chem. Soc., Perkin Trans. 1 1990, 
3085-3089; (h) Novikov, M. S.; Amer, A. A.; Khlebnikov, A. F. Tetrahedron Lett. 2006, 47, $639-642$.

4. (a) Balli, H.; Huys-Francotte, M.; Schmidlin, F. Helv. Chim. Acta 1987, 70, 2045-2057; (b) Kim, C.-H.; Marquez, V. E. J. Org. Chem. 1987, 52, 1979-1983; (c) Kartsev, V. G.; Gizatullina, E. M. Chem. Heterocycl. Compd. 1991, 27, 672; (d) Dias, M.; Richomme, P.; Mornet, R. J. Heterocycl. Chem. 1996, 33, 1035-1039; (e) Reisinger, A.; Koch, R.; Wentrup, C. J. Chem. Soc., Perkin Trans. 1 1998, 2247-2250; (f) Reisinger, A.; Bernhardt, P. V.; Wentrup, C. Org. Biomol. Chem. 2004, 2, 246-256; (g) Reisinger, A.; Koch, R.; Bernhardt, P. V.; Wentrup, C. Org. Biomol. Chem. 2004, 2, 1227-1238; (h) Addicott, C.; Wentrup, C. Aust. J. Chem. 2008, 61, 592-599; (i) Addicott, C.; Bernhardt, P. V.; Wentrup, C. ARKIVOC 2009, (vi), 30-37.

5. (a) Shutalev, A. D.; Fesenko, A. A.; Cheshkov, D. A. Goliguzov, D. V. Tetrahedron Lett. 2008, 49, 4099-4101; (b) Fesenko, A. A.; Tullberg, M. L.; Shutalev, A. D. Tetrahedron 2009, 65, 2344-2350; (c) Fesenko, A. A.; Trafimova, L. A.; Cheshkov, D. A.; Shutalev, A. D. Tetrahedron Lett. 2010, 51, 5056-5059; (d) Fesenko, A. A.; Shutalev, A. D. Tetrahedron, 2011, 67, 6876-6882; (e) Fesenko, A. A.; Trafimova, L. A.; Shutalev, A. D. Org. Biomol. Chem. 2012, 10, $447-462$.

6. For reviews on anti-aromaticity, see: (a) Breslow, R. Acc. Chem. Res. 1973, 6, 393-398; (b) Schmidt, R. R. Angew. Chem. Int. Ed. 1975, 14, 581-654; (c) Minkin, V. J.; Glukhovtsev, M. N.; Simkin, B. Y. Aromaticity and Antiaromaticity: Electronic and Structural Aspects; Wiley: New York, 1994. (d) Wiberg, K. B. Chem. Rev. 2001, 101, 1317-1331; (e) Allen, A. D.; Tidwell, T. T. Chem. Rev. 2001, 101, 1333-1348; (f) Randić, M. Chem. Rev. 2003, 103, 3449-3605.

7. (a) Schleyer, P. v. R.; Maerker, C.; Dransfeld, A.; Jiao, H.; Hommes, N. J. R. v. H. J. Am. Chem. Soc. 1996, 118, 6317-6318; (b) Subramanian, G.; Schleyer, P. v. R.; Jiao, H. Angew. Chem. Int. Ed. 1996, 35, 2638-2641; (c) Gogonea, V.; Schleyer, P. v. R.; Schreiner, P. R. Angew. Chem. Int. Ed. 1998, 37, 1945-1948.

8. (a) Fukui, K. Acc. Chem. Res. 1981, 14, 363-368; (b) González, C.; Schlegel, H. B. J. Phys. Chem. 1990, 94, 5523-5527. 